$\begin{array}{ll} & \text { Etnográfica } \\ \text { etnográfica } & \text { Revista do Centro em Rede de Investigação em }\end{array}$

Antropologia

vol. 14 (3) | 2010

Vol. $14(3)$

\title{
Food and sociability on the contemporary Brazilian plate
}

Comida e sociabilidade no Brasil

\section{Livia Barbosa}

\section{(2) OpenEdition \\ Journals}

\section{Edição electrónica}

URL: https://journals.openedition.org/etnografica/209

DOI: 10.4000/etnografica.209

ISSN: 2182-2891

\section{Editora}

Centro em Rede de Investigação em Antropologia

\section{Edição impressa}

Data de publição: 1 outubro 2010

Paginação: 567-586

ISSN: 0873-6561

\section{Refêrencia eletrónica}

Livia Barbosa, «Food and sociability on the contemporary Brazilian plate», Etnográfica [Online], vol. 14

(3) | 2010, posto online no dia 21 outubro 2011, consultado o 11 fevereiro 2022. URL: http:// journals.openedition.org/etnografica/209 ; DOI: https://doi.org/10.4000/etnografica.209

\section{(cc) (i) \&}

Etnográfica is licensed under a Creative Commons Attribution-NonCommercial 4.0 International License. 


\title{
Food and sociability on the contemporary Brazilian plate
}

\section{Livia Barbosa}

\begin{abstract}
The main purpose of this article is to explore the relationship between food and sociability. Although this is a theme often approached in Anthropology, the true role of food in this relationship is seldom made explicit. Based on three different empirical researches, the article identifies the kind of sociability that is established in each meal in accordance with the day of the week, indicating for each case the degree of relevance assumed by food itself. Following the daily sequence of the different meals - breakfast, lunch and dinner -, the data presented allows for the discussion of the definition of sociability as developed by Simmel and its application to the context of Brazilian society.
\end{abstract}

KEYWORDS: food, food consumption, sociability, weekdays, Brazilian society.

IT IS IMPOSSIBLE TO SPEAK ABOUT FOOD AND NOT ALSO SPEAK ABOUT sociability and social relations. Statements implying that the acts of feeding oneself or eating are governed by rules - indicating with whom we eat, what we eat, and under which circumstances - abound in the literature. In fact, Lévi-Strauss, in his modern classic Culinary Triangle (1968), already pointed out that, through meals, we can identify the foundations of "social algebra".

Through nutrition and food we build identities and territories, through its distribution and its access we speak of power and hierarchies, and through rituals we identify values and social classifications (Douglas and Isherwood 1979). Food consumption works as a central mechanism of mediation and objectification, as much as any other aspect of the material culture of a society, through which we build and reproduce social relations, values, identities, and cosmologies (Keating 2000; Renne 2007; Paulson 2008; Halperin 2008).

Though emphasized in the literature, the relationship between food and sociability is more frequently stated than expanded upon. The focus tends to be more on consecrated ritual moments like Christmas or Easter or on certain meals within the domestic space rather than outside the home, with almost no 
emphasis on the types of sociability permeating meals. Descriptions of ritual procedures, the joint production of food offering and the rules and conventions of food distribution are frequent in the literature, but these involve little discussion, if at all, of food as such. Neither does the literature focus on the impact of food on different types of sociability. Although always invoked as an important element, food seldom appears as an actor with its "own lines" imposing itself beyond its role as a mediator and reproducer of social relations. This absence of a more explicit and detailed presence of food in contemporary studies is in sharp contrast with the recent centrality of food in the media and in our lives as a theme for discussion. Ranging from gastronomy to nutrition, scientific and popular articles and books fill the shelves of bookstores, the pages of magazines, the headlines of newspapers and the screens of television sets. Similarly, whether from the political, the environmental, or the ideological perspective, food has never before been so used as an instrument of citizenship and conscious consumption. Even the ludic and entertainment dimensions of food have entered the scene. Previously viewed as time-consuming, labor intensive and socially menial work, cooking has become valued as a hobby, and food as an object of aesthetic pleasure. In addition, paralleling literary works in which taste, flavor, and textures are the main characters, a flourishing filmography has brought crowds to the movies and transformed the act of speaking about food into a best-selling genre of entertainment.

More recently, literature on food and social relations has incorporated a new discussion on the destructive roles of globalization and modernization. These views focus on the decreasing number of meals eaten together by families, the individualization of the diet in Europe and the United States, and the loss of legitimacy of traditional institutions in defining modern societal values, including those relating to food and nutrition. According to this argument, people are increasingly eating in a solitary and individual manner, the time reserved for meals is being reduced to a functional minimum, and the traditionally related activities of eating and socializing are on their way to becoming excluded from the menu of several societies.

In this article, I am interested in mapping and discussing the sociological links between food, social relations, and sociability, in the context of Brazilian daily meals inside and outside the home. The thesis defended here is that the relationship between food, social relations, and sociability does not seem to be at risk within the framework of Brazilian society. However, the character of that sociability, the type of social relations, and the food served are defined by the combination of place - at home or outside -, day of the week, and context (DaMatta 1985; Barbosa 1984). The mentioned variables determine not only the nature of the predominant relationships and sociability related to meals, but also the lesser or greater role played by food as a central "character", with its own density, in the different situations. 
While distinguishing between social relations and sociability, this article uses the concept developed by Simmel (Levine 1971; Frúgoli 2007) in a new light. To Simmel, the notion of sociability does not imply any specific purpose on the part of the people involved. The contact, the exchange, and the conversation are the final purposes of the relationship. This is the opposite of what happens in social relations driven by some other specific aim, be it commercial, professional, or religious (among others). In these cases, sociability is no longer the central principle permeating the relations and becomes only a formality.

It is my view that this distinction established by Simmel is too extreme and rigid to account for all concrete social situations within the context of Brazilian society, where it is very hard to find social relations that are not intermeshed with sociability, in the sense posited by Simmel, as the desire for interaction and exchange without a defined purpose. Based on this assertion, I use the concept of sociability in a wider sense to designate the different qualities of interactions that may occur in the course of a meal.

\section{THE RESEARCH}

This article is based upon three different pieces of empirical research, conducted at different times, by the author. The first was a qualitative and quantitative study on Brazilian food habits, carried out in 2006. In this instance, over 2000 questionnaires were applied and analyzed, in addition to 400 interviews undertaken in the context of focus groups, in ten cities of over one million inhabitants accounting for each region of the country. ${ }^{1}$

The two other pieces of research were conducted in 1984 and 2006 in three Brazilian cities (Rio de Janeiro, São Paulo, and Porto Alegre), investigating representations of the days of the week in Brazilian society. Both used in-depth interviews and gave rise to the articles "Because today is Saturday: a study on the representations of the days of the week" (Barbosa 1984) and "Still Saturday" (Barbosa 2006). Separated by a 22-year time span, both studies involved roughly the same type of data, with some variations focusing specifically on young people and adolescents that will not be a central concern here. For the first study, 10 female factory workers and 17 female employees with secondary and higher educational levels, from several organizations, were interviewed. In the second, I maintained the same proportion of women of those two labor categories and added 12 young people of both genders in the

1 This survey was conducted by Toledo Associados and CAEPM-ESPM. The questionnaire included questions about the number of daily meals, what was eaten in each one, who decided the menu, who was responsible for shopping, the differences between weekdays, weekends and ritual meals, the meaning of each of them, the manners at the table, time-length of the meal, and talks around the table, the meaning of cooking, the presence of men and women in the kitchen and so on. More detailed data from the research can be found in Barbosa (2007). 
age range of 17 to 22 years old. In the second case, the 10 factory employees were replaced by maids that are structurally similar to the factory workers in terms of income and level of education. The data from all three surveys have been integrated into the present article and serve as an empirical base for the thesis defended.

This article is structured in three parts. The first presents the representations of the days of the week and how they affect what, how, and with whom a particular individual is going to eat. The second analyzes the meals of both weekdays and the weekends and the social relations and sociability involved; and finally, the third part interprets these data in the light of Simmel's concept of sociability, and the rereading I propose.

\section{REPRESENTATION OF THE DAYS OF THE WEEK}

The representations made of the days of the week indicate that from a symbolic point of view, the Brazilian week is divided into two distinct temporal segments - weekdays and weekends - with different values, logics, and practices (albeit interrelated). Although according to the official calendar the first day of the week is Sunday, from this representational viewpoint it is part of the "weekend" category, together with Saturday. The "week" itself runs from Monday morning until Friday at the end of working hours. Friday evening is an ambiguous space: it is not the "weekend" but neither is it part of the "week".

Weekdays and weekends shape a hierarchical classification along an axis ranging from positive to negative in terms of expectations. Both the positive and the negative expectations are related to the greater or lesser degree of individualized moments that prevail along the day, moments when one's will is the normative subject of one's actions. The more individualized the day or its temporal segment is (morning, afternoon or night) the more positive are its classifications. ${ }^{2}$ Fundamental here is the feeling of autonomy and freedom. It is necessary to bear in mind that we are not speaking about a concrete evaluation of specific days among a specific category of people, but about days and abstract temporal segments like Friday, Saturday, and/or weekend.

These positive and negative representations create an emotional curve along which expectations grow, up to a maximum point that is reached on Friday evenings and throughout Saturdays (the two favorite times of most respondents), then decreases to a lower level beginning on Sunday afternoon reaching its lowest point at Sunday night and remaining in this low position

2 Certainly there were and are other variables influencing the perception of days, like vacations, proximity of holidays, or specific activities relating to life cycle and gender in particular, but these are not our central concern in this study. 
through Monday morning, at which point the curve starts a new ascending trajectory.

This emotional curve materializes in quite distinct attitudes, behavior, social relations, and activities which can be observed not only within the domestic group but also within the public sphere. Depending on the day, restaurants are more or less crowded, meals last longer or end sooner, people dress in a more or less refined manner, and individuals eat with people with whom they maintain different social relations.

When we apply this curve representing the days of the week to the meals within and outside the home we observe that weekdays meals predominantly involve familial and workplace social relations and types of sociabilities, which I would classify as "recognition", "functional", and "affective". Meals during the weekend are characterized by the presence of extra-familial social relations and "existential" sociabilities, which can be understood as the equivalent of the concept of sociability as defined by Simmel.

The same pattern occurs when observing the types of food ingested. Their presence and valuation obey approximately the same scheme, varying according to day, meal, and whether the meal is eaten inside or outside the home. Let us now have a more detailed look at the data.

\section{MEALS AND SOCIABILITY ON WEEKDAYS}

\section{Breakfast}

Of the weekday meals, breakfast involves the least sociability, regardless of the place where it is eaten (i.e., at home, in the street, or at work). It is the meal that most people have at home ( $77 \%$ of the sample), characterized by the involvement of almost exclusively family members. Yet it is not, according to a large portion of our sample population (44\%), a meal that brings all the family together. For this reason, commensality and sociability inherent at other times are absent from breakfast. Even for those who consider breakfast a meal that unites the family (38\% of our sample population) it is necessary to qualify how this union is understood. It may or may not take place around a table (it does in the case of the 60-65 age range), and this "family" aspect generally refers to the presence of all members of the family inside the house early in the morning, and not to the act of eating together.

On average, it is the meal during which people talk the least and perceive that they have less time to eat (generally indicating that they have breakfast in only 10 or 15 minutes). The pressure of a social macro time endowed with its own dynamics that submits the micro time of individuals is felt in the adjustment of personal rhythms. Thus, some individuals get up or would like to get up earlier to have more time to have a "good breakfast", whereas others report exactly the opposite (as is the case with younger individuals). Younger 
individuals tend to sleep until the last possible minute and leave home without breakfast, or instead eat or drink something portable on the way to their destination (like Toddy, yogurt, or biscuits).

Black coffee is usually common at home. At around 6 AM, my husband and I have a black coffee. My son has a cup of yogurt, and then goes to school, at 8 . That is when I have a beautiful breakfast, with a glass of milk and a bread roll. My husband also takes a sandwich, which he eats after he is "already working". If we are at home at weekends, then it is the law of the "gaucho", we make mate tea non-stop. [Woman, C segment, PA]

I have breakfast while getting my daughter ready. [Woman, C segment]

Breakfast is the most "stable" meal in terms of the menu. Regarding this meal, few or no claims are made about individual preferences and variety on the part of family members. Even though most people consider it an important meal in terms of health and a good start to the day, it is basically frugal. The basic menu is the same for most people, including coffee, milk, and bread - regardless of income, age range or region of the country (Barbosa 2007). Concerning this menu, commentaries are nonexistent regarding taste, flavor, and texture. Breakfast foods are never mentioned in the list of favorite types of food, even if individuals make statements like those: "I love having breakfast"; "This is my favorite meal"; "That smell of coffee being strained is simply divine"; "French bread with butter is the best thing in the world, I need nothing else".

These types of statements generally occur in social contexts in which individual preferences are introduced as a way of relating oneself to another, when that which we conceive of as "being yourself" is defined in terms of your tastes and preferences. Through these tastes and preferences, social relations are reaffirmed or built up (Campbell 2004). This type of comment on personal preferences in terms of food also appears when sensory stimulus, such as the smell or sight of something, brings back specific memories. On these occasions, speaking about personal preferences is a way to establish or deepen connections with other individuals.

Even though emphatic statements about the breakfast menu, like the ones previously listed, do exist, individuals hardly ever make them when asked about what they most enjoy eating. Foodstuff pointed out as favorite by most people is always part of lunch, dinner or dessert menus. Although men mentioned "churrasco" (barbecue) as their favorite dish more frequently than women, when we compare the items of preference lists for both sexes there is almost no difference. To summarize, within the context of the other meals, breakfast is not "top of the mind" in terms of taste, variety, or abundance. 
Breakfast is also the meal at which the antinomies described by Warde (1997) and Barbosa (2007) for the choice of what to eat are seldom present. During the interviews, the questions raised by mothers and wives about what to serve regarded lunch and dinner, both during the week and the weekend, but never what to serve for breakfast.

Breakfast taken at home is a low-sociability meal. Little or no speaking takes place, and when conversation does exist, we can define this speaking as a sociability of "existential recognition" and/or "domestic functionality". In the case of existential recognition, it is said that people speak so that silence does not impose itself and is not interpreted - as it is frequently in Brazil - as social distance, a quarrel, or ill will among individuals with affection links. Even if people do speak, there is no real conversation: no exchange of experiences, flow of topics, or longer phrases. However, if we take a closer look at this type of social interaction, we can consider it to be a pure state of sociability, insofar as it aims at nothing but explicitly admitting the presence of the other, and recognizing that this presence is existentially important to an individual and deserves to be recognized by one's speech. Hence, what is spoken may involve a broad array of topics, but nothing very specific. Comments like "I slept badly last night", "I couldn't get to sleep", or "one more week ahead" are representative examples of what is spoken as part of this "recognition sociability".

In the case of "domestic functionality" sociability, the conversation is about daily/weekly obligations and tasks. Included in this type of conversation may be anything necessary for the family's social and physical reproduction, regardless of its nature. References to what may be in the newspaper and to other current events are rare, because most people cannot read the newspaper before leaving home. In fact, for many, not speaking at all would be ideal. Thus having "breakfast in peace" is an objective of a number of mothers. This refers to having breakfast alone, after everybody has left and the bustle is over. Then a mother is able to enjoy her "coffee" (which although literally is just one item of the meal, ends up encompassing, as a term, all other food items, as it stands for "breakfast"), as well as perhaps the newspaper or just the moment.

I don't like speaking at breakfast. I think no one really does. [M., C, RJ]

That depends, on Mondays and Wednesdays I have breakfast in a hurry and on the other days I have it more calmly, but always alone. [Woman, segment C, married]

After everybody leaves, that's when I sit down and have my breakfast, read my paper and treasure every minute. [Woman, segment A, married, with children, RJ] 
Little social interaction, low sociability, and hurry also characterize breakfast taken in the street, at snack vendors, bars, and at work. Little is spoken and many individuals prefer silence. The day is beginning, people are still coming fully awake, and it is the period of the morning in which people are just beginning to reassume the dynamics of social life. In terms of meals, breakfast serves as a rite of passage, through which one regains one's contact with social life and gradually begins to socialize.

Although this may be a roadmap by which we can understand breakfast on weekdays, it does not apply to weekends. On weekends, the micro time of individuals structure domestic routines, allowing the logic of the day to obey a voluntaristic, rather than a hierarchical, principle. Both physical spaces and individualized times are much more plentiful, albeit in competition with those of the family.

What individuals most value at weekend breakfasts are: the ability to eat and digest with calm and tranquility, the additional menu options, and the intense sociability. During the weekend breakfast, food takes on a role of greater importance. Personal preferences appear more strongly, the menu can be better planned, and new items may be added to it (e.g., fruit, eggs, juice, or cake, for the segments of the population with a higher income).

On Saturdays and Sundays when the bread at home is finished, I go and buy it at the bakery. From Monday to Friday breakfast is fast, without much ceremony, but on Saturdays and Sundays, when we are more peaceful and everybody is at home, I have breakfast at nine-thirty, ten o'clock and my wife really likes the kitchen so she makes cakes, cookies and I eat them for breakfast. On Sundays the children and grand-children come to visit us, go to table and eat... [Curitiba, male, income C]

At weekends I bake. I like making croquettes, salty cakes, because the grandchildren come on weekends so I make a lot of things. [Woman, Curitiba, segment C]

Weekend - WOW... We always add something to the frugal menu of the week. Usually scrambled eggs or more fruit and more time. [Woman, segment A, RJ]

The fact that the weekend menu is more elaborate and the binomial taste/pleasure is present still does not mean that people speak more about food and its sensorial impact. When food emerges on the conversational scene, it is generally to denounce something that went wrong, rather than to reaffirm the pleasure of eating: "Didn't you make that cake I like?"; "There is no papaya?!"; "I wish there were some fruit!" 
In Brazil there is not much verbal elaboration about food from a sensorial perspective. Tasting food seems to be an intimate and personal pleasure. However, it is important to note that a lack of conversational elaboration about what people eat does not indicate indifference. It means that, in most cases, the gustative sensation is seen as a private experience.

While little is spoken at breakfast on weekdays, on weekends conversation picks up. Topics include Saturday and Sunday plans, newspaper stories, what is going on in the family, and general news. The feeling is that of relaxation and people linger around the table. Social relations and sociability are predominantly family-oriented. Fathers and sons, and mothers and daughters, engage in gender-specific conversation themes such as shopping, sports, and politics, among others with some interconnections.

More recently, a new trend relating to weekend breakfast has been taking root in large urban centers, mostly among higher-income individuals, but which has also been spreading to other social segments. Here breakfast is taken outside the home in sophisticated bakeries, restaurants, and pleasant locations. It is becoming not just a meal, but a period of leisure time. Foods that characterize this type of breakfast involve menu variety and quantitative abundance: fruit, juice, cake, toast, jam, sliced meats, milk, coffee, chocolate, cereals and yogurt, and several types of bread are mandatory presences, and eggs, omelets, quiches, bacon, and sausages and other types of food may also be included. In many cases, this type of breakfast may also involve alcoholic beverages, more specifically "sparkling wine" added to fresh fruit juice.

Under these circumstances, the conversation regarding food takes on a different density. People make comments about it and plan breakfast in this or that place, referring to specific items: "They have a wonderful blackberry jam"; "For me it is the best waffles on Earth"; "An incredible variety, you just cannot eat all, you feel sorry and when you get home you regret not having eaten more".

This weekend breakfast is not to be understood as a brunch, in the North American sense. The menu does not include dishes that are common to that type of meal, like beans in a lightly sweetened tomato sauce, prime rib, potatoes prepared in several ways, pancakes, or salads. It also takes place at an earlier time than the traditional North American brunch. Usually, breakfast taken outside home here in Brazil lasts until noon at most. The objective is not to combine breakfast and lunch into a single meal, but rather to transform breakfast into a leisurely meal, with a lot of tranquility, relaxation, high sociability with family and friends.

Another trend affecting breakfast in large urban centers is its transformation, as has already occurred with lunch, from a private event into one involving business activities. Clearly inspired by North American culture, this modality of breakfast indicates a growing invasion of business matters from the workplace 
into private life, especially following on the increasing presence of corporate culture in Brazil (Barbosa 2002). This new type of meal seeks to capitalize on time within tight business agendas, making possible the immediate handling of topics that otherwise would probably have to wait for days to be dealt with. The sociability permeating this type of meal is basically that of business, and for this reason it is understood that the ruling principles and the associative interests are those of objectivity and entrepreneurial gains. This may be the meal where formality, in the sense defined by Simmel, predominates, to the detriment of general sociability. The warm-up period preceding these business meetings is much smaller than usually takes place in other contexts. At the business breakfast, even though the chosen locations are sophisticated hotels and/or bakeries, what is eaten receives little or no explicit conversational reference or attention. While the criteria for choice of location certainly include the quality of the food offered in these places, the locational convenience for the participants is what matters the most. Within this context, the sensorial impact of the food is seldom explicitly considered, and performs no relevant role in the introduction to or the nature of conversations.

Even in the context of these new trends (weekend and business breakfasts), breakfast is still the meal taken outside the home by the smallest number of Brazilians, the meal offering the lowest degree of sociability and the lesser variety in social relations. ${ }^{3}$

\section{Lunch}

In only $32 \%$ of the cases studied did the urban Brazilian population consider lunch during the week to be the meal that brings the family together. However, when we consider both urban and rural Brazil together, this proportion reaches $50 \%$ of the respondents, in a sharp contrast to European countries and the United States. What makes lunch still a family meal in Brazil is the fact that children do not attend classes on a full-day basis, as occurs in other countries, and in small and medium cities husbands often still go home for lunch.

A lunch at home in large Brazilian urban centers is a hurried meal, with a lot of coming-in and going-out. It involves a high degree of social interaction and predominantly family relations. There is a lot of speaking but little real conversation. All of the exchange is centered on "what must be done", in terms of the tasks related to the social reproduction of the family group. Mothers, children, grandparents and daily cleaners all circulate around the house carrying out their tasks and articulating schedules among themselves. Although

3 Favorite places for those having breakfast outside the home are bars and snack-bars in $38.2 \%$ of the cases, followed by on-the-job/work cafeterias with 31\%, "kilo restaurants" for 25\% of the sample, à-la-carte restaurants for $15.8 \%$, while $14.5 \%$ choose friends' and relatives' homes, and only $6.6 \%$ prefer fast food restaurants. 
noisier than breakfast, lunch taken at home is not a meal in which the ethos of pleasure and relaxation are present. The macro time regulating street activities invades the home in an impersonal manner, determining the home's internal rhythm.

The choice of which specific foods are eaten has more importance than in the case of breakfast, both in the nutritional and flavor aspects. The choice of a suitable menu is a task which puts a lot of pressure on housewives. Pleasing everyone's tastes, meeting economic conditions, and time availability are factors to be considered, because lunch has to have "substance". In other words, it "carries us" though the rest of the day and therefore, for most Brazilians, it is the most important meal of the day, which nobody "goes without". It is the meal where the antinomies emphasized by Warde (1997) and Barbosa (2007) are more present, generating dilemmas and restrictions on who decides what will be eaten. Still, the role of food is more functional than pleasurable and comments about it, when they arise, are again more in the form of complaints than acclamations. Children are those who most complain, followed by husbands in much smaller proportions. But what do children complain about? They complain about the monotony of the daily menu, and that they do not like to eat what is served on the table. Even though both lunch and dinner meals are composed of several dishes, these are always more or less the same, including rice and beans and some meat and vegetables cooked in different ways.

For mothers, lunch is a tense meal. They hear complaints and try to make children eat what they understand to be nutritionally sound. In fact, mothers of small children see lunch as an arena for disputes over maternal authority, and childish whims and preferences. Eating "food from the pan" or "healthy food" (the traditional beans, rice, meat, and vegetables) is a task imposed on mothers by tradition, pediatricians, nutritionists, and the media (Azevedo 2008).

Lunch is the meal most frequently eaten outside the home by Brazilians. In $54 \%$ of the sample, at least one family member ate out every day. Those who eat out-- mainly men and young people - do so in $83 \%$ of the cases for work or school reasons. Of the latter, $48 \%$ are men, followed by sons and daughters, who account for $26 \%$.

While the main reason for eating out is work or study, this does not mean that people eat alone; on the contrary, 53\% eat with work colleagues, 27\% alone, 15\% with their children, 14\% with their husband, and 13\% with their wife and others. Nor does it mean that the meal is laden with emotional problems. The accompanying conversations to lunches eaten out are very diverse, ranging from spicy gossips to major work events, and including topics like things to do back at the office, future shopping needs, bitter domestic rows, soccer, and romantic accounts about boyfriends. The sociability when having 
lunch outside the home during the week is intense, because it represents a break in a segment of time determined by variables external to the individual. For this reason, the ethos of lunch during the week outside the home is more relaxing and fun than lunch at home. It is an individualizing moment in a hierarchical time and space. This is mainly the case with women who are subject to school schedules, domestic chores, and who do not have a formal time during which external demands are not imposed. Eating out during the week is an individualizing moment in the context of a hierarchic day. But where and what do people eat on these occasions?

People mainly eat in "kilo restaurants" (in which they help themselves from a buffet and payment is by plate weight), snack bars, bars, and à-la-carte restaurants, among other places. ${ }^{4}$ The oft-criticized fast food restaurants appear in only $8 \%$ of the cases. However, when people do eat in these locations what is eaten is not considered real "lunch", but rather a "snack", a "McDonald", or just a "sandwich".

As the week advances, so does the sociability around lunch and even around food quality. Thursdays and Fridays deserve a "better restaurant". This means not only a different and better food but also a more sophisticated establishment and a more refined personal appearance for women.

What people eat in these restaurants varies to a large extent, even in the pervasive presence of rice and beans. This traditional duo of Brazilian cuisine is supplemented by the immense variety of dishes offered in the kilo restaurants, which may include endless numbers of dishes from diverse culinary traditions like lasagna, cannelloni, savory pastries, beef parmigiana, sushi, sashimi, kebab, wine-sauce meat, and a number of salad types, among others. For those eating at snack bars, by and large from lower-income population segments, lunch is close to a home-cooked meal, with the inclusion of the Brazilian tradition of mixing carbohydrates within the same dish and during the same meal. These places usually serve a ready-made dish, or prato feito (also known as $\mathrm{PF}$ ), which normally consists of rice, beans, some meat, fried potatoes, salad, farofa (fried manioc flour) and possibly a fried egg.

Despite the fact that, when eating outside the home, one eats what one likes and eats more variety than is available at home, food is not a topic of conversation during meals, except when the food in question exceeds expectations.

4 The huge success of "kilo restaurants" in Brazil is largely due to the fact that they allow Brazilians to remain loyal to the tradition of eating a hot meal at lunchtime in a fast and efficient manner, as well as offering a large variety of foods. Another favorable aspect of this type of restaurant is that, because it offers varied types of food, it facilitates large numbers of people with different preferences eating together, because each one of them can always find his or her favorite food in this type of place. Recently there have appeared in Brazil the so-called "fast good", fast food networks that, instead of offering the criticized hamburgers with potato chips and soda, offer traditional Brazilian food while using the principles of rationality and "MacDonaldization" (Ritzer 1993). 
Once a set of preferred restaurants is established that people regularly attend, changes are not frequent. Although not a topic of conversation, the act of choosing where to eat and choosing foods that one prefers increases the feeling of individuality of the meal, and therefore the inherent pleasure. That may explain the low rate of complaints from husbands, as opposed to children, concerning homemade food. As these husbands frequently eat out and can then choose what they prefer to eat, when they eat at home they are more tolerant regarding what goes on the table. Plus, they can escape the monotony of daily life on a regular basis.

Men and women in a specific social position, especially those in executive positions, are the main customers of business lunches. In these cases, à-la-carte restaurants are chosen, based largely on the type and quality of food available at a specific location. Guests are intentionally invited to places where the gastronomic experience is considered to be of excellent quality. And in these cases, meetings start with specific moments regarding what people are or will be eating. Therefore, during the "business lunch", food provides the initial push towards sociability, which then proceeds through other socialization steps. It is important to bear in mind that nobody will start a reunion or meeting in Brazil, whatever its nature, by going straight to the point. The so-called "warm-up phase", during which people try to establish connections and which Simmel would certainly define as a formality, is much longer and more varied than that in similar situations among Europeans and North Americans. In Brazil, this period is filled with conversations about issues beyond the realm of business. Personal tastes, hobbies, vacations, family, and friends in common are some of the included topics, aimed at establishing positive social relations of familiarity and social positioning. Through these conversations, it is possible to know "with whom we are talking" (DaMatta 1979), a person's "social and relational capital" (Bourdieu 1984 [1979]), and thus to build relationship networks, which may serve as links, intermediaries, and catalysts for business facilitation.

Sunday lunches are the main meal of the day. Taste, variety, satisfaction of individual preferences, and excesses are the categories associated with this meal. This meal escapes the traditional daily rice and beans, but still varies within a familiar range of options (Barbosa 2007). At Sunday lunches, food receives special attention as an object in itself. It is commented on, celebrated, and often planned in advance during the week.

I start to plan Sunday's lunch on Thursday. [M., Recife, married, segment A]

During the week my husband and son ask me: "Do that on Sunday!" And I try to do it. [M., married, RJ, segment C] 
Sunday at home is always barbecue, there is no other way. [M., POA, segment B]

Every Sunday we have barbecue at home. People come to our swimming pool... it ends at about 5 or 6 pm. [M., Brasilia, segment A]

This means that Sunday lunch, whether taken inside or outside the home, is the one that gathers all of the family around the table, or at least, that is what is currently represented by the data. Family, in this context, may include only the immediate domestic group, but may also commonly include uncles and aunts, cousins, grandparents, grandchildren, and friends.

Sunday's lunch is the longest meal, presenting the strongest schedule dislocation (Herpin 1988). It can start as late as 4 PM and run into the evening. This timing of the lunchtime meal neutralizes the evening meal, which practically ceases to exist within the domestic context - it becomes just a snack, a glass of milk, leftovers from lunch, or one more spoonful from lunch's dessert; it is no longer a real meal, becoming instead a time to "grab something to eat" and, in most cases, there is no type of sociability involved.

Sunday's lunch is also the meal that most commonly has the man "entering the kitchen", mainly when it is a barbecue. In this case, the man of the family is in charge of the meat, while his wife takes care of the side dishes and of the kitchen cleanup. Additionally, close friends participate more intensively in preparing this meal, and within the domestic context, Sunday's lunch is the meal with the highest degree of exo-sociability.

During Sunday lunches, sociability is ruled by emotions arising from the existential experience. Conversations about work and tasks related to the family's physical and social reproduction are given little space. Emphasized are the events and experiences regarding each individual, including future plans and memories alike. Because it is a meal involving high emotional density, it can at times reach cathartic levels, rows and the possibility of honestly venting one's feeling may arise.

Sunday's lunch is followed by the beginning of the period presenting the highest negative classification (Barbosa 1984) of the entire week, in which the question of what to do imposes itself as the "greatest decision" to be made. Sleeping, going to a movie, or just chatting, all work as mechanisms to "bide time" until Sunday is over. It is no longer considered weekend time, because actions are already regulated by the forthcoming activities of the week; however, it is not yet considered the week, and therefore the concept of "activities of the week" is out of place. This advance of a macro time and a hierarchical logic imposed onto micro, individual time, endows this period with a feeling of "emptiness", and an absence of meaning and expectations for many people. The very physical environment of the cities expresses this 
feeling. At restaurants, once the extended Sunday lunch period is finished, flies become the main customers. For this reason, though Monday is considered a bad day for many people (because it is a working day), it is still better than Sunday evening because the expectations that comprise the emotional curve start to be built again.

\section{Dinner}

Dinner during the week is the meal that most brings the family together for relaxation, because there is no school activity, work, or duties to be done after it. The ideology that meals taken together unite families is shared by most Brazilians. This is the moment to talk with the family, to learn about the children's lives, and to talk about what is happening with everyone. Therefore, the presence of television during this time is highly criticized, even though it is, in fact, turned on in $69 \%$ of the homes during the meal. But even while turned on, it does not inhibit conversations. In fact, it can either serve as the topic of a conversation, or it may disappear completely from people's focus of attention and just be a backdrop.

Although ideologically the center of family sociability during weekdays, dinner at home does not necessarily imply eating around a table in a formal manner. Serving one's own plate and taking food straight from the pot to sit in the living room, in front of the television, are common practices. Teenagers eating in their own rooms in front of the television or a computer have also become a more frequently referenced practice, despite strong criticisms.

Dinner at home occurs from Monday through Thursday. On Fridays, it starts to be replaced by a snack, as happens on Saturdays, or by some activity outside the home. Though only 14\% of the studied population have stated that they regularly have dinner out on Fridays, working late, meetings with friends, or some other plan dislocates this meal to a much later time, or perhaps neutralizes it entirely. It is exactly on Friday evening that the transition from week to weekend occurs, and the social relations focused on family give way to other types of relations and sociabilities. Friends and dates replace fathers, mothers, wives, and children. It is a type of sociability centered on friendship and affection. Precisely because people know this, and think of Friday evenings and Saturdays as related to exo-familiar sociability, any events affecting the area of friendship and affection are represented in a more dramatic manner during these two time periods. Friday and Saturday evenings are not deemed to be either family-centered or solitary days. On the contrary, these are days to go out to local hotspots to be seen and to party with friends. Pubs and restaurants, with their increased attendance, demonstrate this change in behavior and attitude. Those establishments located in the city's entertainment areas tend to be crowded more often on Friday and Saturday nights than on weekdays, while the opposite is true for establishments located in urban or 
industrial centers, and which supply food to those working in the surrounding area. Still, as the week advances, within the work environment the prolongations of activity in these places increases, especially in the form of the "quick drink" after work. In this type of activity, alcoholic drinks (beer, draught beer and caipirinhas) and traditional savory foods (croquettes, tarts, typical meat specialties, cupcake-size Portuguese pies, sausages, etc.) take precedence over "dinner", and sociability is in fact the main dish. The objective is the meeting itself, and being with friends, "talking nonsense", "having a chat", "having a chilled lager", "eating something", but always exchanging experiences, feelings, sensations, and opinions. No focus is placed on what is spoken, except as it relates to relishing the company of the "other". Whoever is passing by the downtown areas of large Brazilian cities will certainly see the streets crowded with improvised barbecues in front of bars (preferably run by people from "their group" among those with a lower income), with people standing up or grouped together. For those with a higher income, the "little bars" that offer "happy hours" are favorite options.

As for "dining out" on Saturday evenings, that is a practice limited to the higher-income population. This type of meal is also based on an exo-familiar sociability, but there are some differences regarding the food and the density of this sociability. Whereas on Fridays, and even on Saturdays, sociability has a higher density among younger people and lower-income segments, when it comes to dining out this number is further reduced, and the participants are couples, not individuals. In this context, where to dine and what to eat takes on great importance and food and drinks (mainly wine) gain dimensions previously unseen in the other meals of the week. This is a moment in which the demonstration of a deep and elaborated knowledge of food, drinks, and associated practices is used as an instrument of social distinction, in the strict sense used by Bourdieu (1984 [1979]), among the participants.

More recently, another type of sociability and social interaction has been created in connection with some meals, particularly with Friday or Saturday dinner and Sunday lunch. Here I refer to meetings among relatives and friends - mainly those in the middle or higher spheres of society - during which men, in many cases, go to the kitchen themselves to show off their culinary talents. During these times, food and conversations about food are central themes of the meeting. Welcome topics of conversation include not only the sharing of gastronomic knowledge, but also the sources of ingredients, details of recipes, quality of ingredients, knowledge acquired from cooking, and flavors. Cooking in the presence of a guest, including him or her in the preparation of a meal while sipping a glass of wine, is a new cultural moment in the relationship between food and sociability. Here, food is the main character of the event; no longer simply the mediator of social relations, but the source that engenders these relations and sociabilities. Most of the conversations and the exchange 
of experiences are about the food itself. This is sociability in its pure state, as long as nothing is expected except meeting another person and having the pleasure of food as a central experience. What is interesting about this trend and this type of socialization is that it has brought a newly discovered respect for what is commonly thought of as a chore (cooking), and added a certain nobility to a space in the Brazilian home (the kitchen) which has traditionally been relegated to an inferior status and considered to be the realm of women. Until very recently guests did not enter the kitchens of Brazilian homes. Now all this is changing. Kitchens are not only nicely decorated, but, in some cases, the most valued room in the home, physically connecting with the living room which was traditionally unknown. Another aspect related to the entrance of men into the domestic kitchen is the growing quantity of culinary utensils. When they belong to men, these utensils are of higher quality, made with state-of-the-art materials, and kept separately, for the man's exclusive use, away from wives and maids. Many men now build kitchens specifically for their own culinary adventures. And though the existence of a space specifically for men is a characteristic of higher-income populations, the other transformations have been expanded to the lower social segments. Planned kitchens, sold in popular stores, and utensils specifically for men who enter the kitchen seem to be common among all who enjoy cooking, regardless of the income segment they belong to.

\section{FINAL OBSERVATIONS}

Social relations, sociability and meals are closely related within the context of Brazilian society. Nevertheless, this relation varies in both quality and intensity depending on the type of meal, the day of the week, and the place where the meal is eaten, as indicated by previous data for different types of meals inside and outside the home. Although varying in intensity and content, the relation between sociability and food does not seem to be threatened by globalization, or by the individualization of menus in Brazilian society. On the contrary, food in Brazil is perceived as a source of pleasure, the sociability surrounding the meals is intense, and family unity around a table is a symbolic representation and practice which remains important, despite being pressured by the urban pace of life and the presence of television during meals. Although one may observe a sequentiality in the intake of meals, and a smaller number of meals taken together around a table with all of the family present, it is important to note new forms of social relations and sociabilities regarding food and meals that have appeared in recent years. Chief among them is the weekend breakfast taken outside the home in bakeries, agreeable places, and restaurants, as well as the publicization and socialization of cooking. In the case of the latter, food plays a major role, insofar as a large part of the time involved is spent making 
comments about the food and the impact it has on the senses. However, it is worth pointing out that although it highly values the pleasures of eating, Brazilian society does not seem to have developed a specific vocabulary and discourse about food, as opposed to, say, the French and the Italians. During most meals food goes largely unnoticed, with any comments being generally complaints or regular and flat acclamations. We emphasize here the meals of breakfasts at home, daily home lunches, and other meals during which food, although obviously the main component of a meal has a lesser role as a "character" around the table. In the same vein we highlight Sunday lunch as their symmetrical opposite.

The concept of sociability, as defined by Simmel, insufficiently captures the full dynamics of social relations as pertains in Brazil, whether in relation to meals or other more general cultural aspects. For instance, it is a well-known fact that within Brazilian business culture, as documented in several studies, work and business relations are permeated by the strength of social and family relations (Barbosa 2002; DaMatta 1979). In other words, seldom are these relations dictated only by business affairs. The examples of business lunches and work meetings in Brazil are the most well-known because their duration is much longer than that of similar events in North America. What may account for this difference in duration is precisely the function that sociability performs in these two cultures. In modern North American society, after the initial friendly formalities preceding any meeting, conversation goes straight to business and remains there. In Brazil, these initial formalities last longer, as though some embarrassment prevents people from immediately speaking about business, lest they seem impolite. Another point is the weight of variables related to social relations such as empathy, friendship and so on. To do business with someone I like or come to like strengthens trust in the other person and in the business deal. Thus the traditional warm-up time is much longer, and topics other than those which are business-oriented are common and expected to mingle with business conversation.

I propose a twofold explanation for this permanent conjugation between sociability in Simmel's sense and sociability in the wider sense, which I use to define any exchange among people. First, no social relation, in any society, is as coded and formal as to allow nothing other than the previously determined agenda, except instances of rituals. Second, this mixing of sociability in social relations of a different nature is, to a greater or lesser extent, common, to different social situations. In situations where frontiers between social relations are more rigid and defined, this intermixing occurs less often and with less intensity. In other situations, the opposite occurs, when the boundaries between the different natures of social relations would be less rigid. In the case of Brazilian culture, associative processes involving work and business, social relations that are or should be permeated by some type of formality, 
are difficult to identify in their pure state, in practice. By and large, the frontiers are always ambiguous and the otherwise formal situation is permeated by sociability as defined by Simmel.

This permanent possibility of transforming formalities into sociability is central in Brazil and is also present in the model of social relations in other societies of varying cultures. For some, the meaning and significance of these associations would be primarily oriented towards fulfilling common objectives in specific contexts and situations. For others, as in the case of Brazilian society, the ultimate meaning of these associations would be the existential pleasure of the meeting and the interaction, with any common objective being only secondary. Because associations based on objective interests are crucial for the functioning of any modern society, the ultimate meaning of sociability in Brazilian society would be to permanently invade spaces dominated by other logics.

\section{REFERENCES}

AZEVEDO, B.A., 2008, Construção do Gosto Infantil. Niterói, Universidade Federal Fluminense, masters dissertation.

BARBOSA, L., 1984, "Porque hoje é sábado... Um estudo das representações dos dias da semana", Boletim do Museu Nacional, 49.

—, 2002, "Globalização e cultura de negócios", in A. M. Kirschner (ed.), Empresas, Empresários e Globalização. Rio de Janeiro, Relume Dumará, 21 1-226.

— 2006, "Still Saturday: symbolic representation of weekdays", mimeo.

— 2007 , "Feijão com arroz e arroz com feijão: o Brasil no prato dos brasileiros", Horizontes Antropológicos, 13 (28): 87-116.

BOURDieu, P., 1984 [1979], Distinction: A Social Critique of the Judgment of Taste. London, Routledge.

CAMPBELL, C., 2004, "I shop, therefore I know that I am: the metaphysical foundations of modern consumerism", in K. Ekström and H. Brembeck (eds.), Elusive Consumption: Tracking New Research Perspectives. Oxford, Berg, 27-44.

DaMATTA, R., 1979, O Que Faz o Brasil, Brasil. Rio de Janeiro, Rocco.

— 1985, A Casa e a Rua. São Paulo, Brasiliense.

DOUGLAS, M., and B. ISHERWOOD, 1979, The World of Goods: Towards an Anthropology of Consumption. New York, W.W. Norton.

FRÚGOLI, H., 2007, Sociabilidade Urbana. Rio de Janeiro, Zahar Editores.

HALPERIN, M., 2008, "Something good to go", available at <www.qsrmagazine.com/articles/menu_development/107/portable-1.phmtl>. 
HERPIN, N., 1988, "Le repas comme institution: compte rendu d'une enquête exploratoire”, Revue Française de Sociologie, XXIX: 503-521.

KEATING, E., 2000, "Moments of hierarchy: constructing social stratification by means of language, food, space, and the body in Pohnpei, Micronesia", American Anthropologist, 102 (2): 303-320.

LEVINE, D., 1971, Georg Simmel on Individuality and Social Forms. Chicago, Chicago University Press.

LÉVI-STRAUSS, C., 1968, O Triângulo Culinário. São Paulo, L’Arc Documentos.

PAULSON, S., 2008, "Body, nation, and consubstantiation in Bolivian ritual meals", American Ethnologist, 33 (4): 650-664.

RENNE, E.P., 2007, "Mass producing food traditions for West Africans abroad", American Anthropologist, 109 (4): 616-625.

RITZER, G., 1993, The MacDonaldization of Society. London, Sage Publications.

WARDE, A., 1997, Consumption, Food and Taste. London and Thousand Oaks, Sage.

Comida e sociabilidade no Brasil - Livia Barbosa - Center for Advanced Studies in Advertising and Marketing (CAEPM) at the Advanced School of Advertising and Marketing (ESPM), Brazil • lbarbosa@espm.br

Neste artigo procurei aprofundar a relação entre comida e sociabilidade. Embora este seja um tema sempre invocado pela antropologia, o papel da comida e do alimento nesta relação quase nunca é explicitado. Baseado em três diferentes pesquisas empíricas, este trabalho procura indicar o tipo de sociabilidade que se estabelece em cada refeição de acordo com o dia da semana, precisando para cada uma delas qual o grau de protagonismo que a comida desempenha. Organizado em seções de acordo com as três refeições - café da manhã, almoço e jantar - os dados abrem espaço para uma discussão da definição de sociabilidade proposta por Simmel e como ela se aplica no contexto brasileiro.

PALAVRAS-CHAVE: comida, consumo alimentar, sociabilidade, dias da semana, sociedade brasileira. 